\title{
A comparative analysis among Standard Load Profiles for Natural Gas consumption simulation at urban scale
}

\author{
Laura Canale $^{1}$, Gino Cortellessa ${ }^{1}$, Marco Dell' Isola ${ }^{1}$, Giorgio Ficco ${ }^{1}$, \\ Andrea Frattolillo ${ }^{2}$, Fabrizio Zuena ${ }^{1}$, Alfredo Castaldi ${ }^{3}$ \\ ${ }^{1}$ Università di Cassino e del Lazio Meridionale, Cassino, Italy \\ ${ }^{2}$ Università di Cagliari, Cagliari, Italy \\ ${ }^{3}$ Salerno Energia Distribuzione, Salerno, Italy
}

\begin{abstract}
The aim of this research is to evaluate the performance of official natural gas allocation methods currently applied within natural gas network of three EU Member States, with a view to simulating energy consumption of urban building stocks. The models have been used to estimate natural gas consumption of an urban building stock with Non-Daily Metered (NDM) customers at two scales: city and neighbourhood. To this end, these methods have been applied to a distribution network in Southern Italy with about 16000 NDM customers and 4000 buildings. The present research gives useful information about the accuracy of natural gas billing for NDM customers.
\end{abstract}

\section{Introduction}

Generally speaking, estimation, forecasting and profiling energy demand and consumption at both urban and larger scales (neighbourhoods, cities, energy networks etc.) are, undeniably, fundamental tools for energy management. In fact, they represent a key issue in numerous contexts, such as planning building retrofitting strategies and energy production (Massimo et al. 2014), reducing $\mathrm{CO}_{2}$ emissions, capacity allocation, price estimation, continuity of supply, estimation of unaccounted gas (Arpino et al. 2014) etc..

With particular reference to the Natural Gas Networks (NGN), in many EU Countries the vast majority of final users is represented by small residential and commercial utilities with heating, cooking, hot water production and cooling purposes (ACER 2017). Their consumption is usually metered only few times a year and for this reason they are identified as Non-Daily Metered (NDM). In fact, despite the Third Energy Package (European Commission 2009a, European Commission 2009b) requires Member States to ensure implementation of smart metering systems for all final users, this obligation is conditional on a positive economic assessment of the long-term costbenefit analysis and a specific implementation program for smart metering in the gas sector has not even been set (European Commission 2014). In this direction, only five EU Member States (Ireland, Italy, Luxembourg, Netherlands and UK), decided to carry out smart meters rollout in the gas sector by 2020 to allow a daily metering of final users, while twelve will not even proceed with the gas meters rollout, as the results of the cost-benefit analysis were negative. Besides, forecasting and estimating models may be useful tools also for building stocks fully metered by means of smart gas meters, when energy consumption loads have to be reconstructed due to failures of the measurement or the transmission systems.

Methods established in the scientific literature to simulate the building energy consumption at urban scale belong to different categories. The so-called bottom-up engineering models simulate the energy consumption of buildings through suitable physically based equations with a number of parameters such as thermo-physical characteristics of the urban building stock, installed heating systems and their real operation, human behaviour, climate data etc. (Kavgic et al. 2010). These models generally produce fixed "building typologies" (Canale et al. 2018, Ballarini, Corgnati and Corrado 2014, Ballarini and Corrado 2017), in which it is possible to classify the existing building stock. It is clear that estimates of this kind of models strongly depends on the quality of data, whose availability is, moreover, not always guaranteed. On the other hand, top-down models typically estimate the aggregate energy consumption of a building stock by establishing a relationship between the energy use and different drivers such as socio-economic indicators, household size, technologies and practices, weather condition, etc. (Li et al. 2017). The aggregate building energy demand of a region is increasingly subdivided into smaller sections, being suitable only for particular purposes, i.e. at estimating increased energy consumption of new buildings or reduced energy consumption before or after retrofit interventions (Reinhart and Davila 2016). Within top-down models, data-driven approaches start from real energy consumption data coming from smart-metered district or cities, and by means of suitable techniques (machine learning algorithms, regression methods etc.) they make predictions by learning from historical data (Amasyali and El-Gohary 2018, Kontokosta and Tull 2017). These last usually require the use of a huge amount of data (i.e. smart meters data) during training phase, which are of course not always available for NDM customers.

Indeed, energy network managers, as well as the competent authorities, are required to make estimates with a limited number of significant parameters and with a high level of accuracy, in order to continuously supply industrial and domestic consumers and to avoid dangerous service interruption. As highlighted by Oliver et al. (2017) in Europe, simple, lumped-parameters models are used to estimate gas consumption for general forecasting and gas management of NDM customers (allocation for balancing purposes). These represent a sort 
of "hybrid" models, a cross between the bottom-up and the data-driven approaches (also referred as "bottom-up statistical" (Kavgic et al. 2010)), which are mainly regression-based methods (UK, Ireland, France, Italy) making use of climate-related variables and particular dummy variables for weekends, holidays, holiday seasons etc. These models are generally employed for consumption allocation purposes (for energy balancing of the NGN) and make energy consumption estimates and forecasts in a given period (month, year etc.) by means of: i) energy consumption within a random period, ii) climatic variables (outdoor temperature, wind speed, temperature of the previous days etc.) and iii) Standard Load Profiles (SLP) obtained from samples of frequently read users (day/intra-day frequency) clustered by end use category.

When it comes to simulating the energy consumption of residential building stocks, whose characteristics may be mainly unknown (e.g. thermo-physical building parameters, plant configuration, behavioural aspects and so on), this kind of simple, hybrid models could be useful for both the initial calibration and the validation phases of the simulation method and could stand as useful tools also for energy simulators.

In this context, the authors investigated three different NG allocation methods of three major EU countries with the aim of assessing the accuracy of using these last to effectively predict the energy consumption of a building stock at urban scale. The aim of this work is also to provide an innovative view on the possibility of using these models, mainly employed for energy network management, as a support tool for simulation and forecasting of the consumption of urban building stocks. The methods analysed are currently in use in Italy, Germany and United Kingdom, which are the main countries for NG consumption within Europe and are therefore considered representative of the technical and regulatory state of the art on this subject. To this end, the case study of a building stock in Southern Italy with about 16000 NDM and 4000 buildings is presented and discussed. The performances of the investigated methods have also been evaluated at two different spatial scales, city and neighbourhood, by determining the monthly and yearly errors from the real measured values.

\section{Methods and Data}

\section{Allocation methods for NDM customers}

Modelling methods used by European transmission system operators to estimate NDM natural gas consumption are generally employed for consumption allocation purposes (e.g. energy balancing of the NGN and billing). Natural gas consumption estimates and forecasts are obtained through:

i) two meter-readings per year within a random period (generally 2 or 6 months);

ii) climatic variables (outdoor temperature, wind speed, temperature of the previous days etc.)

iii) SLPs whose main characteristics and parameters are defined within specific standards and technical documents by each EU Member States; SLPs are mostly regression-based curves with variable regressors.

In all the three investigated methods (Italian, German and English) each NDM customer is first assigned with an end-use category, which identifies either the final use of the natural gas (heating, cooking, hot water production, cooling, technological use etc.) or the size, in terms of natural gas consumption of the customer (Joint Office of Gas Transporters 2017, Nationalgrid 2016, ARERA 2016, BDEW/VKU/GEODE 2018, FfE 2015).

The estimation of the annual NG consumption $\left(\mathrm{NDM}_{\mathrm{AC}}\right)$ and daily $\mathrm{NG}$ consumption $\left(\mathrm{NDM}_{\mathrm{DC}}\right)$ of each NDM user is then performed as reported in equations (2) and (1).

$$
\begin{gathered}
N D M_{D C}=C V \cdot S L P_{d} \cdot C F_{d} \\
N D M_{A C}=C V \cdot \sum_{d=1}^{365} S L P_{d} \cdot C F_{d}
\end{gathered}
$$

Where $C F$ is the correction factor for weather conditions, day of the week, holidays etc., $S L P_{d}$ is the Standard Load Profile defined by the national regulation and $C V$ represents the Customer Value, which is a measure of the "amplitude" of the load profile of the customer, being directly related to two meter-readings at days 1 and n $\left(L_{1}\right.$ and $L_{n}$ ), as per equation (3).

$$
C V=\frac{L_{n}-L_{1}}{\sum_{d=1}^{n} S L P_{d}}
$$

The three analysed methods, although presenting methodology similarities, differ for SLP and climate

\begin{tabular}{|c|c|c|}
\hline \multirow{2}{*}{ IT } & SLP & $\begin{array}{l}\text { SLPs are given via a specific equation, } \\
\text { whose parameters are fixed by the National } \\
\text { Authority as a function of climate, of the } \\
\text { customer type etc. }\end{array}$ \\
\hline & Climate & $\begin{array}{l}\text { There is no explicit weather variable in the } \\
\text { equation. Weather is however taken into } \\
\text { account in the equation parameters which } \\
\text { are defined by climatic zone. }\end{array}$ \\
\hline \multirow{2}{*}{ UK } & SLP & $\begin{array}{l}\text { SLPs are defined as a proportion of the } \\
\text { average seasonal normal demand. Seasonal } \\
\text { cut-offs and turn-on are used to better } \\
\text { manage seasonal conditions. SLPs are } \\
\text { defined and updated by a third party basing } \\
\text { on samples of smart-metered users. }\end{array}$ \\
\hline & Climate & $\begin{array}{l}\text { A Composite Weather Variable (CWV) is } \\
\text { defined to linearize the daily NDM } \\
\text { Demand. The weather data used for the } \\
\text { CWV are temperature and wind speed and } \\
\text { a set of parameters that provide a linear } \\
\text { relationship to demand. }\end{array}$ \\
\hline \multirow[t]{2}{*}{ DE } & SLP & $\begin{array}{l}\text { Two different variations of SLPs are given, } \\
\text { which are both temperature-dependent } \\
\text { sigmoid-like curves to which seasonal } \\
\text { specific space heating and water heating } \\
\text { terms are added to account for seasonal } \\
\text { peculiarities. }\end{array}$ \\
\hline & Climate & $\begin{array}{l}\text { An "allocation temperature" is defined, } \\
\text { calculated as geometric series of the } \\
\text { temperatures measured within the } \\
\text { forecasting day and the previous } 3 \text { days, to } \\
\text { consider the heat capacity of buildings. }\end{array}$ \\
\hline
\end{tabular}
definition as described in Table 1.

Table 1: End-use categories of the analysed sample 
For synthesis reasons, it was not possible to accurately describe the profiling methods adopted by each state, for which the reader is referred to the references in the bibliography for further details.

Due to a non-disclosure agreement between the third party and the network operators, authors could not access to the UK regression coefficients of the defined customer profiles. However, in the presented case study authors built their own profile by applying the UK methodology to the real natural gas consumption of residential customers for the year 2017.

\section{Case study and dataset}

The case study analysed in this paper is represented by a local distribution NGN located in Southern Italy supplying 3828 residential buildings (climatic zone C, 1134 Heating Degree Days). The NGN is made up of 15980 NDM customers equipped with G4 gas meters (Ficco et al. 2016a) and about 80 Daily-Metered (DM) customers equipped with smart gas meters (i.e. all greater than G4, according to the rollout program). These latter measure NG consumption of small and medium industries and public offices including also few apartment buildings equipped with centralized heating system. In detail, 48 DM users are large and medium industrial users and the remaining 32 are public offices and apartment buildings equipped with centralized heating system (domestic use). For sake of simplicity, in the present analysis, the authors will refer to the energy consumption of NDM users, DM public offices and domestic users as "Residential", identifying with this label utilities with heating, cooking, hot water production and cooling purposes.

An overview of the analysed urban building stock is given in Figure 1.

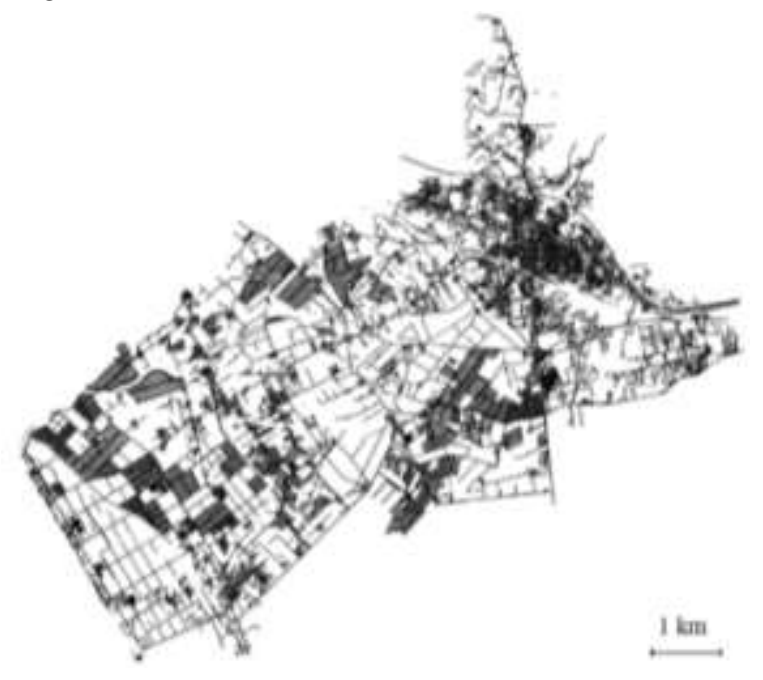

Figure 1: The analysed building stock

For this study, three sets of data, provided by the distribution company, were available:

1. NDM meter readings within a period of about three years between 2015 and 2017;

2. DM meter readings from smart gas meters within the year 2017 on a daily basis;

3. total natural gas supplied to the network, in the year 2017 on a daily basis.
Regarding NDM readings, although Italian regulation establishes a minimum requirement of two attempts of meter reading per year, the actual availability of data for each NDM users is conditioned to the accessibility to the gas meter in absence of the customer (i.e. gas meter inside or outside the property). Thus, within the given period, the number of readings is not the same for all users and some readings are also missing in the considered period. In these cases, an average customer value has been assigned basing on the end user category.

The application of the described methods, of course, required an effort to adapt the Italian end user categories, which were already assigned to each customer of the dataset, into German and English ones. This has been possible thanks to additional information provided by the distribution company, which allowed to identify the type of use of both technological and residential customers.

Only $3 \%$ of end user category was not known and it has not been possible to get this information elsewhere. For this limited set of users, the authors chose to replicate the sample distribution and to allocate the end user categories by preserving the same proportion observed in the assigned dataset.

Climatic data (temperature, solar radiation, wind speed, relative humidity etc.) are weather historical simulation data, and have been provided by the Swiss weather service provider meteoblue $A G$ (www.meteoblue.com).

\section{Estimate of NG consumption \& model performance evaluation}

The real natural Gas Consumption of Residential customers $(R G C)$ for space heating, cooking, hot water production and space cooling purposes in the given period (days from 1 to 365 of the year 2017), has been measured as the difference between the Total natural Gas Consumption $(T G C)$ of the network and the Industrial natural Gas consumption (IGC) as per equation (4):

$$
R G C_{\text {meas }}=\sum_{d} T G C_{d}-\sum_{d} I G C_{d}
$$

Where index $d$ varies between 1 and 365. The total $R G C$ has been estimated by the authors as the summation of two contributions: the total NDM load, estimated by means of the methods described in paragraph \#2.1, and the total, known, residential DM load as per equation (5):

$$
R G C_{e s t}=\sum_{d} \sum_{i} N D M_{D C_{i, d}}+\sum_{d} \sum_{k} N D M_{D C_{i, d}}
$$

where indices $d, i$ and $k$ vary, respectively, between 1 and 365 , between 1 and 15980 and between 1 and 12. Finally, the knowledge of the real $R G C$ allowed the authors to calculate the relative error $(e)$ of the natural gas consumption estimated by means of the investigated method on a monthly, seasonal and yearly basis, as per equations (6), (7) and (8) and thus, to evaluate the model performance when applied at urban scale.

$$
\begin{gathered}
e_{\text {month }}=\frac{R G C_{\text {est,month }}-R G C_{\text {meas }, \text { month }}}{R G C_{\text {meas }, \text { month }}} \\
e_{\text {season }}=\frac{R G C_{\text {est }, \text { season }}-R G C_{\text {meas }, \text { season }}}{R G C_{\text {meas }, \text { season }}} \\
e_{\text {year }}=\frac{R G C_{\text {est }, \text { year }}-R G C_{\text {meas }, \text { year }}}{R G C_{\text {meas }, \text { year }}}
\end{gathered}
$$


Figure 2 shows an overview of the methodology applied to determine the error of the analysed methods.

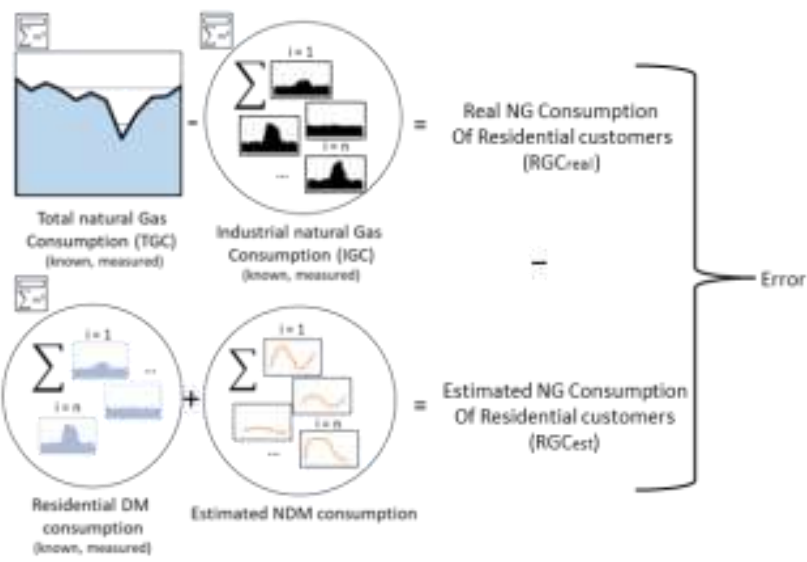

Figure 2: Overview on the methodology applied to determine the error of the analysed methods

\section{Results and discussion}

\section{Building-stock scale}

Results of the application of the described methodologies are shown in Figure 3 and in Table 2, respectively on monthly and yearly basis. In Table 2, the same analysis is also shown aggregating the data for both the heating and the non-heating season.

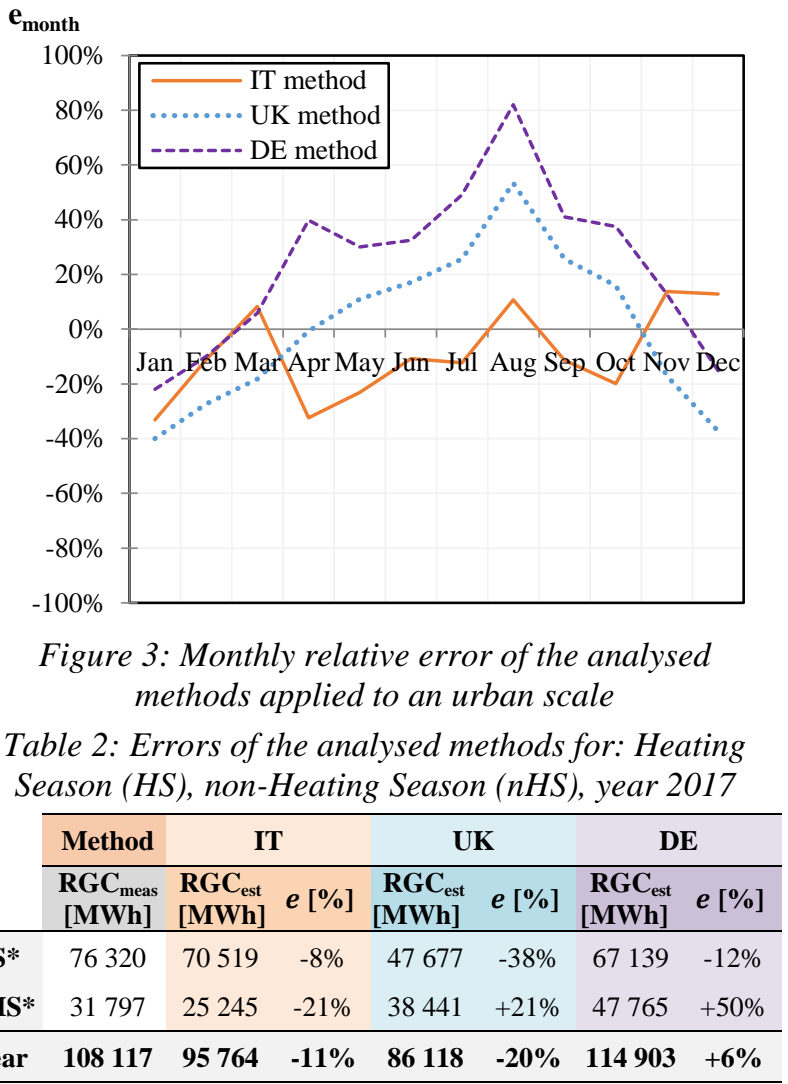

As highlighted in Figure 3 and Table 2, the investigated methods present high errors, which however, were smoothed on yearly basis resulting in far smaller values.

A consideration has to be done regarding the month of January 2017. In this case, in fact, all the methods greatly under-estimated the measured energy consumption of the building stock due to an exceptionally cold weather that occurred in Europe, affecting Central-Southern Italy as well. For the way it is defined (i.e. accounting for meter reading of previous years), the model is not capable to effectively describe extreme weather conditions.

As expected, Italian method performs better if compared to the other ones, as a result of the fact that the methods are applied to an Italian urban energy network. In fact, the application of SLPs defined for building stocks located in continental or cold climates (such as the German and the English ones) to Mediterranean ones, can result in lower quality. This should also explain why both the German and the English methods greatly over-estimate the energy consumption during summer months (from June to September), where also the gradual emptying of cities during July and August should be considered as one of the main uncertainty contributions.

Nevertheless, it has to be highlighted that, considering only the heating season, the German method presents performances comparable with those of the Italian one, sometime giving better results. It is in the opinion of the authors that this strictly depends on the fact that the German SLPs are temperature-dependent curves, whereas for the Italian ones the climatic dependence is based only on the climatic zone and not on punctual temperature data. On the other hand, the UK method always: i) underestimated the energy consumption of the urban network during heating months (January to March, November, December), ii) over-estimated the energy consumption of the urban network during non-heating months. The low performance of the English method is probably due to the composite weather variable, which is built on the specific continental climate (i.e. wind and temperature) and not on Mediterranean one (i.e. temperature and solar radiation). In Figure 4 the results of the energy simulation performed with the described methods are shown, highlighting their error from the measured residential energy consumption.

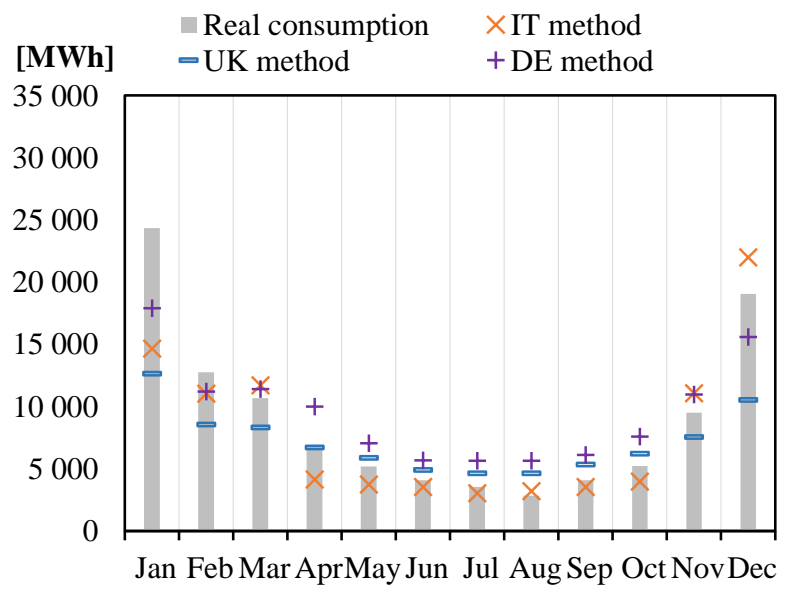

Figure 4: Monthly consumption and relative error of the analysed methods

The application of these models was possible since, for the analysed case study, industrial users were all DM. This, however, represents a fairly replicable condition on most of the European natural gas networks as, generally, users with great energy consumption, as the industrial 
ones, are DM. Definitely, the greater the number of DM users (both industrial and residential), the lower will be the estimation error of the proposed methodology.

Regarding the estimated energy consumption errors, these are mainly due to DM users and NDM users. Regarding the first one, errors are mainly related to different devices and completeness of the measurement chain (Ficco et al. 2015) and could be statistically neglected; on the contrary, NDM users' systematic errors are due to:

- $\quad$ to the drift of the meters, that in some cases are very old meters (Ficco et al. 2016b, Ficco 2014);

- inaccurate user categorization;

- accuracy of SLPs given by national regulations and used to model final users' behaviour;

- number and accuracy of climatic data;

- frequency of successful meter-readings and period in which these have been performed.

In the authors' opinion, among all the above-mentioned contributions, the one related to the frequency of meterreadings has the greatest weight. In fact, the energy consumption of the users is extremely variable over time and depends on numerous variables, such as the weather conditions within the readings, the number of people and the occupancy coefficient, the propensity to energy saving.

Data in Figure 4 and in Table 2 have been calculated with almost one meter-reading per year per final user. The estimation error greatly decreases with increasing number of readings per year and simultaneously performing "reconciliation" sessions. For this reason, the authors simulated four scenarios of successful meter-readings attempts: i) almost one meter-reading per customer, per year, without reconciliation (scenario \#0); ii) two meterreadings per customer, per year (scenario \#1); iii) four meter-readings per customer, per year (scenario \#2) iv) six meter-readings per customer, per year (scenario \#3).

The different scenarios have been simulated under the hypothesis of $100 \%$ successful meter-readings, evenly distributed among the entire year 2017. This implicitly means that, on monthly basis:

- $\quad$ in scenario \#0, none of the users presents error equal to zero;

- $\quad$ in scenario \#1, one sixth of the users presents error equal to zero;

- $\quad$ in scenario \#2, one third of the users presents error equal to zero;

- $\quad$ in scenario \#3, half of the users presents error equal to zero.

In the following, Figure 5 shows the monthly standard deviation $(\sigma)$ for each of the applied method, while Figure 6 shows the yearly error under the different scenarios. $\sigma$

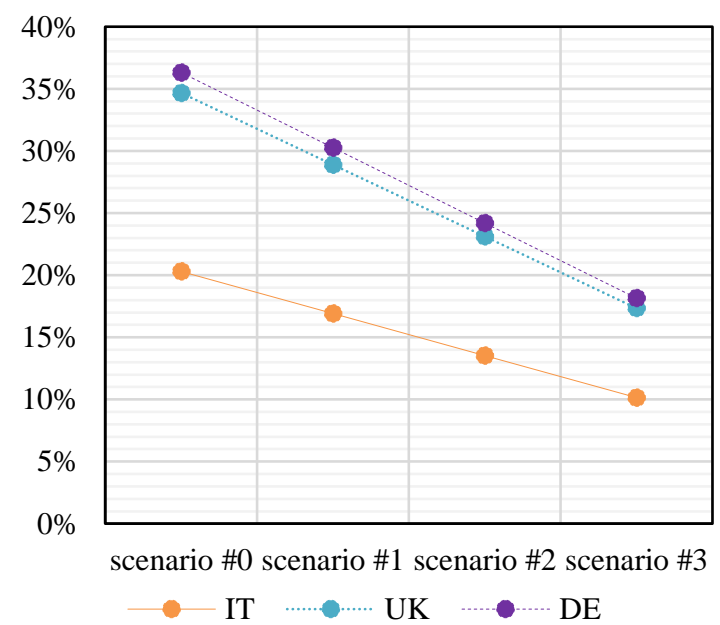

Figure 5: Mean monthly standard deviation of the methods in each scenario, year 2017

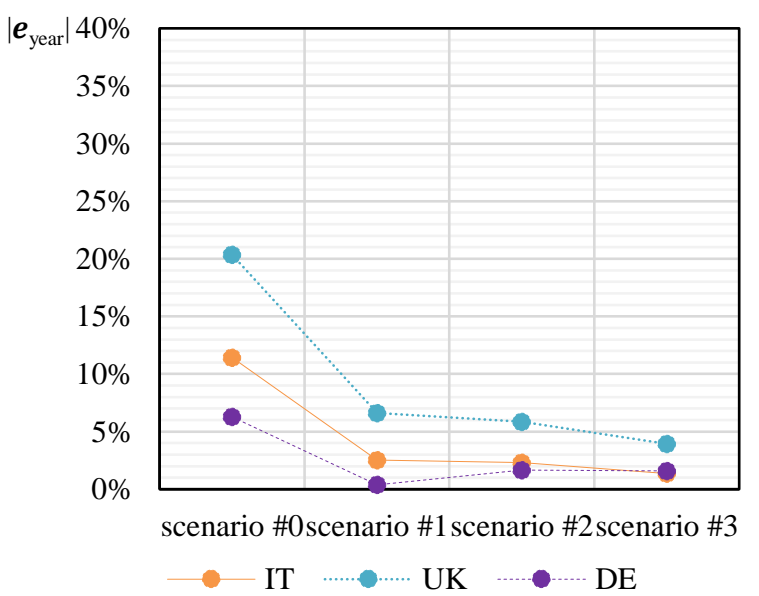

Figure 6: Year error of the methods in each scenario, year 2017

Both the monthly standard deviation and the yearly error strongly decrease with increasing number of meterreadings, reaching absolute values respectively of about $10 \%$ and $2 \%$ with the Italian method. In fact, under the mentioned hypothesis, the yearly forecasting errors under scenario \#0 (which were about $-11 \%,-20 \%$ and $+6 \%$ respectively for the Italian, English and German methods) all decrease below 5\%, as shown in Figure 6 .

Thus, the high potential of these methods for forecasting purposes is evident. This is particularly true if one considers that in Italy, and even in most of EU Countries, NG distribution companies are obliged to perform at least 2 meter-reading attempts per year (scenario \#1).

\section{Neighbourhood scale}

Finally, the authors applied the Italian method (that showed the best performance at the urban scale) at a neighbourhood scale, by simulating the energy consumption of 5 buildings, whose energy consumption was remotely read by suitable smart gas meters and heating, cooking and hot water production services were available. The investigated buildings are shown in Figure 7. 


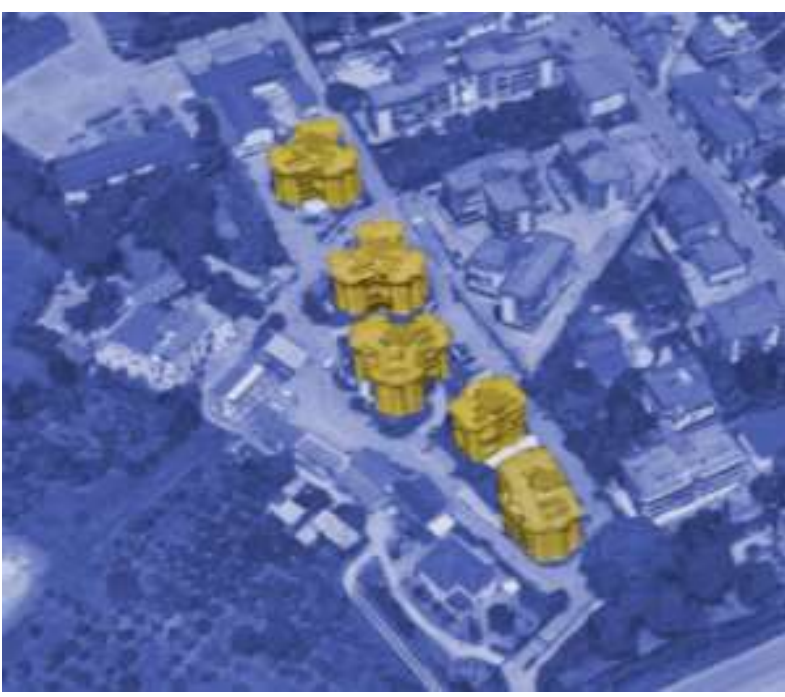

Figure 7: Analysed neighbourhood

A number of one meter-reading during the forecasting year has been used for the investigated buildings. This allow to update the $C V$, calculated as per equation (3).

Figure 8 shows the results in terms of monthly error between the estimated and the measured energy consumption.

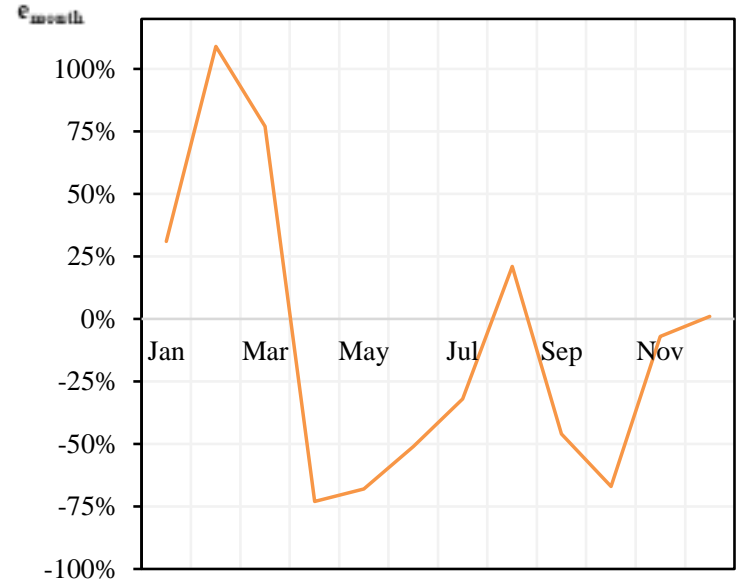

Figure 8: Monthly error of the analysed method applied to a neighbourhood scale

In Table 3 measured and estimated energy consumption of the analysed neighbourhood are shown in terms of seasonal absolute energy consumption and error.

Table 3: Measured and estimated energy consumption with relative seasonal errors, year 2017

\begin{tabular}{lccc} 
& Method & \multicolumn{2}{c}{ IT } \\
\cline { 2 - 4 } & $\begin{array}{c}\mathbf{R G C}_{\text {meas }} \\
{[\mathbf{k W h}]}\end{array}$ & $\begin{array}{c}\mathbf{R G C}_{\text {est }} \\
{[\mathbf{k W h}]}\end{array}$ & $\boldsymbol{e}[\%]$ \\
\hline HS$^{*}$ & 213374 & 303443 & $+42 \%$ \\
nHS* $^{*}$ & 78295 & 32691 & $-58 \%$ \\
\hline Year & $\mathbf{2 9 1 6 6 9}$ & $\mathbf{3 3 6} \mathbf{1 3 3}$ & $\mathbf{+ 1 5 \%}$ \\
\hline *Heating Season (HS), non-Heating Season (nHS)
\end{tabular}

As expected, when reducing the scale of application of the model to a limited number of buildings, the error considerably increases, as a result of the lack of compensation effects, with a quietly different trend respect to the one observed at urban scale. Nevertheless, the seasonal error seems to be higher during the nonheating season, where the expected energy consumption of the five buildings is greatly under-estimated. This is due to the fact that the selected neighbourhood consists of new buildings with better thermal performance than the average ones. On the contrary, during the heating season, the model tends to over-estimate the energy consumption. This is probably due to the fact that some users may have started to heat their houses in October (i.e. before the official beginning of the heating season, which is $15^{\text {th }}$ November for climatic zone $\mathrm{C}$ ).

With the aim to evaluate more precisely the accuracy of the model with reference to the SLP, for the specific case of the neighbourhood, also the daily trend of the load profile estimates of the Italian method have been analysed. This allowed the authors to highlight the effect of a meter-reading during the forecasting year on the estimated consumption profile (i.e. the effect of the CV update during the forecasting year) as shown in Figure 9. This last, in particular, shows the results of the performed analysis in terms of both measured and estimated daily energy consumption, respectively with and without $C V$ update.

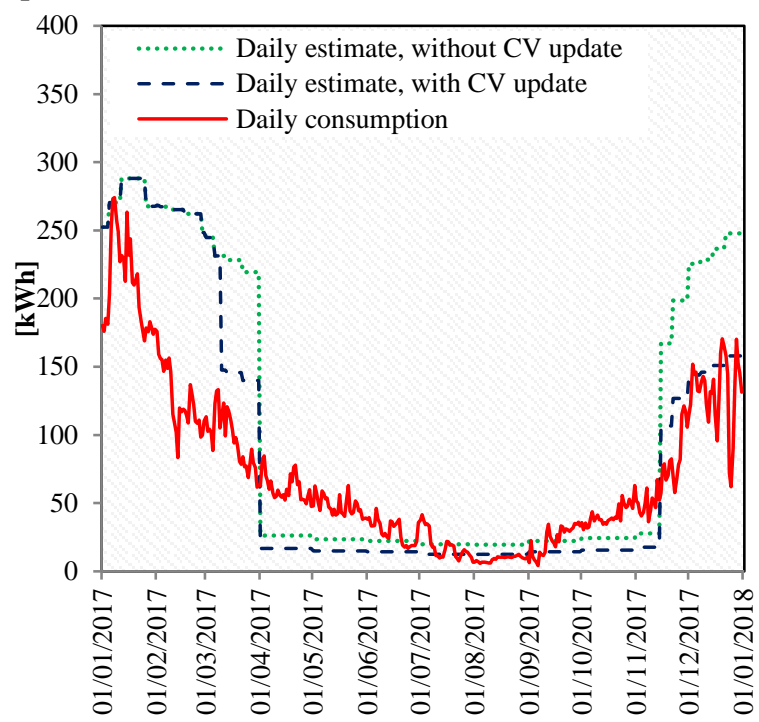

Figure 9: Comparison between the real and estimated consumption of the neighbourhood under the defined scenarios

By analysing the data in Figure 9, it is clear that the application of the model is strongly affected by the frequency of meter-readings and also by the period in which the meter-reading is performed. In fact, a meterreading within the simulated year (March 2017) strongly improves the performance of the model, reducing the gap between the measured and the estimated energy consumption.

\section{Conclusions}

In this paper the authors described and applied the Italian, English and German natural gas allocation methods to estimate the energy consumption of an urban building stock at city and neighbourhood scales. The investigation has been performed in a natural gas distribution network located in Southern Italy having about 16000 NDM customers and about 4000 buildings. The selected neighbourhood was made up of 5 buildings supplied by 
centralized heating system for heating, cooking and hot water production purposes, remotely read.

Overall, among the analysed methods, the Italian method performed better than the other ones. This however represented an expected result, as a consequence of the fact that the methods are applied to an Italian urban building stock. Authors are completely confident in the results of the application of IT and UK methods on the analysed network, where both climatic conditions and customers' categorization have been accurately estimated. On the other hand, the application of DE method may be affected by a certain error due to the lack of detailed customers' categorization (which is available only for the German network). Nevertheless, the results of the present analysis suggest that the German method, presents high potentialities to give better performance if energy signatures (i.e. SLP) of Italian customer categories rather than German ones would be used. To achieve this goal, this would rather require a preliminary clustering of the end-users (i.e. using proper clustering algorithms specifically targeted for time-varying profiles) that would allow a proper categorization and profiling of the final users.

Regarding the lower performance of the English method, this is probably due to missing information about regressor coefficients of English customer categories.

Referring only to the Italian method, at urban scale the proposed methodology always gives reliable results. In case of less than one meter-reading per year, errors were within the range $-8 \%,-27 \%$ respectively during the heating and non-heating season. On a year basis, the error decreased to $-11 \%$. Under the hypothesis of increased number of meter readings per year, the error decreased below $2 \%$, which is considered to be far acceptable considering the simplicity of the defined method. Furthermore, the overall calculated errors seem to have the same magnitude as those obtainable with more accurate bottom-up models.

At neighbourhood scale, consistently with similar scientific literature about building stocks energy simulation, the mean seasonal error of the model increases to $-40 \%,+60 \%$ respectively for the heating and nonheating season. On a year basis, the model still performs well, with an error of about $+15 \%$. The possibility to compare the results obtained with the measurements of the buildings energy consumption, allowed also the authors to highlight the importance of updating the model with a higher number of meter-readings, for a greater consistency of the model.

The proposed modelling approach to residential energy consumption at urban scale has the main limitation to not providing high flexibility to energy consumption simulation. SLPs are, in fact, suitably built on large samples of DM users chosen as representative of the urban building stock and usually updated at large interval of times. Also, they rely on historical energy consumption, which means that are not capable to account for extreme weather scenarios, for changes in the building stock energy efficiency and for end-users' behaviour. For the same reason, they have limited capacity to assess the impact of energy conservation measures.

Nevertheless, the authors think that the present research gives an innovative view on the use of simple forecasting tools towards energy simulation of urban building stocks. This could be particularly useful in case of missing data about thermo-physical parameters of buildings within a building stocks and about energy consumption patterns of users. In fact, few data are required for the application of these models: two meter-readings, climate data and the final energy use of the customer. These last are generally easily available in urban energy networks. For this reason, these models could be used as support tools for the energy simulations of urban building stocks during the calibration and validation phases in absence of accurate data.

Future researches will be focused on improving the performance of the proposed methodology, by analysing new energy signatures taking into account also climatic parameters such as solar radiation, which are relevant for the simulation of Mediterranean building stocks.

\section{Acknowledgements}

This work has been developed under the projects "PRIN Riqualificazione del parco edilizio esistente in ottica NZEB" funded by MIUR (grant number 2015S7E247_002). The authors thank Salerno Energia Distribuzione and meteoblue $A G$ for the data provided.

\section{Nomenclature}

$\begin{array}{ll}\text { CV } & \text { Customer Value } \\ \text { DE } & \text { German } \\ \text { DM } & \text { Daily-Metered } \\ \text { EU } & \text { European } \\ \text { IT } & \text { Italian } \\ \text { IGC } & \text { Industrial natural Gas Consumption } \\ \text { NDM } & \text { Non-Daily Metered } \\ \text { NDM }_{\text {AC }} & \text { Annual NG consumption of each NDM user } \\ \text { NDM }_{\text {DC }} & \text { Daily NG consumption of each NDM user } \\ \text { NGN } & \text { Natural Gas Network } \\ \text { RGC } & \text { Real natural Gas Consumption of Residential } \\ \text { SLP } & \text { customers } \\ \text { TGC } & \text { Standard Load Profiles } \\ \text { UK } & \text { United Kingdom }\end{array}$

\section{References}

ACER. 2017. ACER Report on the implementation of the Balancing Network Code. ACER - Agency for the Cooperation of Energy Regulators.

Amasyali, K. \& N. M. El-Gohary (2018) A review of data-driven building energy consumption prediction studies. Renewable \& Sustainable Energy Reviews, $81,1192-1205$

ARERA. 2016. Testo integrato delle disposizioni per la regolazione delle partite fisiche ed economiche del servizio di bilanciamento del gas naturale, TISG Allegato A (in Italian). 
Arpino, F., M. Dell'Isola, G. Ficco \& P. Vigo (2014) Unaccounted for gas in natural gas transmission networks: Prediction model and analysis of the solutions. Journal of Natural Gas Science and Engineering, 17, 58-70.

Ballarini, I., S. P. Corgnati \& V. Corrado (2014) Use of reference buildings to assess the energy saving potentials of the residential building stock: The experience of TABULA project. Energy Policy, 68, 273-284.

Ballarini, I. \& V. Corrado (2017) A New Methodology for Assessing the Energy Consumption of Building Stocks. Energies, 10.

BDEW/VKU/GEODE. 2018. Abwicklung von Standardlastprofilen Gas (in German).

Canale, L., M. Dell'Isola, G. Ficco, B. Di Pietra \& A. Frattolillo (2018) Estimating the impact of heat accounting on Italian residential energy consumption in different scenarios. Energy and Buildings, 168, 385-398.

European Commission. 2009a. Directive 2009/72/EC concerning common rules for the internal market in electricity and repealing Directive 2003/54/EC.

European Commission (2009b) Directive 2009/73/EC concerning common rules for the internal market in natural gas and repealing Directive 2003/55/EC.

European Commission. 2014. Benchmarking smart metering deployment in the EU-27 with a focus on electricity. (COM(2014) 356 final). Brussels.

FfE. 2015. Weiterentwicklung des Standardlastprofilverfahrens Gas (in German).

Ficco, G. (2014) Metrological performance of diaphragm gas meters in distribution networks. Flow Measurement and Instrumentation, 37, 65-72.

Ficco, G., L. Celenza, M. Dell'Isola, A. Frattolillo \& P. Vigo (2016a) Experimental evaluation of thermal mass smart meters influence factors. Journal of Natural Gas Science and Engineering, 32, 556-565.

Ficco, G., L. Celenza, M. Dell'Isola \& P. Vigo (2016b) Experimental comparison of residential heat accounting systems at critical conditions. Energy and Buildings, 130, 477-487.

Ficco, G., M. Dell'Isola, P. Vigo \& L. Celenza (2015) Uncertainty analysis of energy measurements in natural gas transmission networks. Flow Measurement and Instrumentation, 42, 58-68.

Joint Office of Gas Transporters. 2017. Uniform Network Code - Transportation principal document, Section $\mathrm{H}$ - Demand estimation and demand forecasting.

Kavgic, M., A. Mavrogianni, D. Mumovic, A. Summerfield, Z. Stevanovic \& M. Djurovic-Petrovic (2010) A review of bottom-up building stock models for energy consumption in the residential sector. Building and Environment, 45, 1683-1697.

Kontokosta, C. E. \& C. Tull (2017) A data-driven predictive model of city-scale energy use in buildings. Applied Energy, 197, 303-317.

Li, W. L., Y. Y. Zhou, K. Cetin, J. Eom, Y. Wang, G. Chen \& X. S. Zhang (2017) Modeling urban building energy use: A review of modeling approaches and procedures. Energy, 141, 2445-2457.
Massimo, A., M. Dell'Isola, A. Frattolillo \& G. Ficco (2014) Development of a Geographical Information System (GIS) for the Integration of Solar Energy in the Energy Planning of a Wide Area. Sustainability, 6, 5730-5744.

meteoblue AG. www.meteoblue.com.

Nationalgrid. 2016. Gas demand forecasting methodology.

Oliver, R., A. Duffy, B. Enright \& R. O'Connor (2017) Forecasting peak-day consumption for year-ahead management of natural gas networks. Utilities Policy, 44, 1-11.

Reinhart, C. F. \& C. C. Davila (2016) Urban building energy modeling - A review of a nascent field. Building and Environment, 97, 196-202. 